\title{
Nonmotor Symptoms and Cognitive Decline in de novo Parkinson's Disease
}

\author{
Kyum-Yil Kwon, Sung Hoon Kang, Minjik Kim, Hye Mi Lee, Ji Wan Jang, \\ Ju Yeon Kim, Seon-Min Lee, Seong-Beom Koh
}

\begin{abstract}
Background: Cognitive impairments are common in Parkinson's disease (PD). Despite its clinical importance, the development of dementia is still difficult to predict. In this study, we investigated the possible associations between non-motor symptoms and the risk of developing dementia within a 2-year observation period in PD. Methods: A total of 80 patients with PD participated in this study. Nonmotor symptoms (the Nonmotor Symptoms Questionnaire), PD status (Unified Parkinson's Disease Rating Scale), depression (Geriatric d Depression Scale or Montgomery-Asberg Depression Scale), stereopsis and severity of nonmotor symptoms (Non-motor symptoms scale) were assessed. Global cognitive function (Mini-Mental State Examination) were evaluated at baseline and 2 years later. Results: Presence of depression, vivid dreaming, REM sleep behavior disorders, hyposmia, abnormal stereopsis, non-smoking and postural instability/ gait disturbance phenotype were associated with a significantly more rapid decline of Mini-Mental State Examination. Logistic regression analyses demonstrated that depression (odds ratio $=13.895$ ), abnormal stereopsis (odds ratio $=10.729$ ), vivid dreaming (odds ratio $=4.16$ ), REM sleep behavior disorders (odds ratio $=5.353$ ) and hyposmia (odds ratio $=4.911$ ) were significant independent predictors of dementia risk within 2 years. Postural instability/ gait disturbance phenotype and age $>62$ years were also independent predictors of dementia risk (odd ratio $=38.333$, odds ratio $=10.625$ ). Conclusions: We suggest that depression, vivid dreaming, REM sleep behavior disorders, hyposmia and abnormal stereopsis are closely associated with cognitive decline, and that presence of these nonmotor symptoms predict the subsequent development of Parkinson's disease dementia.
\end{abstract}

RÉSUMÉ: Symptômes non moteurs et déclin cognitif dans la maladie de Parkinson de novo. Contexte: Le déficit cognitif est fréquent dans la maladie de Parkinson (MP). Malgré son importance clinique, l'apparition de la démence demeure difficile à prédire. Dans cette étude, nous avons examiné l'association possible entre les symptômes non moteurs et le risque de présenter une démence au cours d'une période d'observation de 2 ans chez des patients atteints de MP. Méthode: Quatre-vingt patients atteints de MP ont participé à cette étude. Les symptômes non moteurs (Nonmotor Symptoms Questionnaire), le stade d'évolution de la MP (Unified Parkinson's Disease Rating Scale), la stétéopsie et la sévérité des symptômes non moteurs (Nonmotor symptoms scale) ont été évalués. La fonction cognitive globale (Mini-Mental State Examination) a été évaluée au début de l'étude et 2 ans plus tard. Résultats: La présence de dépression, de rêves intenses et troublants, de troubles du comportement du sommeil paradoxal, d'hyposmie, d'anomalies de la stéréopsie, le fait d'être non-fumeur et l'instabilité posturale/la démarche anormale étaient associés à un déclin significativement plus rapide du score au Mini-Mental. Les analyses de régression logistique ont montré que la dépression (rapport de cotes $(\mathrm{RC})=13,895)$, la stéréopsie anormale $(\mathrm{RC}=10,729)$, les rêves intenses et troublants $(\mathrm{RC}=4,16)$, les troubles du comportement du sommeil paradoxal $(\mathrm{RC}=5,353)$ et l'hyposmie $(\mathrm{RC}=4,911)$ prédisaient de façon indépendante le risque de démence au cours des 2 prochaines années. Une instabilité posturale/une démarche anormale et un âge supérieur à 62 ans prédisaient de façon indépendante le risque de démence $(\mathrm{RC}=38,333, \mathrm{RC}=10,625)$. Conclusions: Nous proposons que la dépression, les rêves intenses et troublants, les perturbations du comportement du sommeil paradoxal, l'hyposmie et la stéréopsie anormale sont étroitement associés au déclin cognitif et que la présence de ces symptômes non moteurs prédit l'apparition subséquente de la démence dans la maladie de Parkinson.

Keywords: Nonmotor symptoms, hyposmia, depression, stereopsis, dementia, Parkinson's disease

doi:10.1017/cjn.2014.3

Can J Neurol Sci. 2014; 41: 597-602

Dementia related to Parkinson's disease (PD) is associated with increased mortality, ${ }^{1}$ reduced quality of life, ${ }^{2}$ and increased caregiver distress $^{3}$ and is a major risk factor for nursing home placement. ${ }^{4} \mathrm{~A}$ patient with $\mathrm{PD}$ is five to six times more likely to have dementia than an age-matched control without PD. ${ }^{5}$ Increasing age is the most important risk factor for PD dementia (PDD), and it is more likely to occur in the postural instability and gait disturbance motor phenotype than in the tremor dominant phenotype of PD. ${ }^{6}$ Among non-motor symptoms (NMS), psychosis including visual hallucinations has been associated with increased risk of PDD. ${ }^{7}$ Cognitive dysfunction is related to neurocirculatory abnormalities, especially orthostatic hypotension and supine hypertension. ${ }^{8}$ However, it is uncertain whether various NMS are risk factors for dementia in PD.

From the Department of Neurology and Parkinson's Disease Centre (KYK, SHK, MK, HML, JWJ, SML, SBK), Korea University Guro Hospital, Korea University College of Medicine; Parkinson/Alzheimer Center (JYK), Department of Neurology, Asan Medical Center, University of Ulsan College of Medicine, Seoul, Korea.

Received November 22, 2013. Final Revisions Submitted April 1, 2014. Correspondence to: Seong-Beom Koh, Department of Neurology and Parkinson's Disease Centre, Korea University Guro Hospital, Korea University College of Medicine, \#148 Gurodong Road, GuroKu, Seoul, Republic of Korea, 152-703.

Email: parkinson@korea.ac.kr 
Recently, we suggested that deficits of stereopsis are common in drug-naïve PD patients. ${ }^{9}$ Our previous voxel-based morphometry study suggested that abnormal stereopsis implicated cortical visual dysfunction as part of the NMS in PD. ${ }^{10}$ The involvement of extra-striate visual cortices is also associated with visual hallucinations, one of the high risk factors for dementia in PD. ${ }^{11}$ These findings suggest that abnormal stereopsis, which is related to the visual association area, may be a predicting factor for dementia in PD.

In this present study, we studied the decline of Mini-Mental Status Examination (MMSE) scores over two years according to the presence of NMS including stereopsis. To define the possible associations between NMS and the risk of developing dementia, we investigated the risk factors for dementia conversion within a two-year observation period in PD.

\section{Methods}

\section{Standard protocol approvals, registrations, and patient consent}

The study was approved by the Korea University Guro Hospital Institutional Review Board. All patients provided written informed consent.

\section{Subjects}

We recruited consecutively drug-naïve PD patients, meeting the United Kingdom Parkinson's Disease Society's criteria for idiopathic PD, from the Parkinson's Disease Center at Korea University Guro Hospital from November 2008 to August 2010. ${ }^{12}$ To ascertain dopaminergic drug treatment response, we reviewed medical records of all included patients for two years. Exclusion criteria were as follows: (1) history of head trauma, stroke, exposure to anti-dopaminergic drugs, or central nervous system (CNS) infection; (2) abnormal thyroid function testing; (3) structural lesions or hydrocephalus on brain magnetic resonance imaging (MRI); (4) abnormal cognitive function (MMSE $\leq 24$ ) and (4) red-flag signs suggesting Parkinson plus syndrome. We classified PD patients into either a dementia converting group or a dementia non-converting group.

\section{Clinical assessment}

Patients underwent a neurologic examination and a clinical assessment. Symptom history, level of education, comorbid diseases and medication history were assessed. The Hoehn and Yahr (H\&Y) stage was determined, ${ }^{13}$ and the degree of disease severity was quantified by the Unified Parkinson's Disease Rating Scale (UPDRS). ${ }^{14}$ The Non-motor Symptoms Scale for Parkinson's disease (NMSS) was used to evaluate the presence and severity of NMS. Depression was rated with the Korean version of the Montgomery-Asberg Depression Scale (K-MADS) ${ }^{15}$ or the Geriatric Depression Scale-15. ${ }^{16}$ We assessed olfactory function using structural screening questionnaires including odor detection, discriminatuion and identification. Rapid eyeball movement (REM) sleep behavior disorders (RBD) was screened with RBD screening questionnaires. ${ }^{17}$ The two-step test for stereopsis was performed. The first step involved tests for visual acuity and strabismus. Patients with strabismus, nystagmus, ocular motility disturbance, or poor visual acuity in either eye $(<20 / 40$ Snellen fraction) were excluded from the study. The second step involved the measurement of stereopsis. Stereopsis was assessed using Titmus stereotest plates (Stereo Optic Co., Inc., IL, USA). Normal stereopsis was defined as an arc $<60$ seconds in the Titmus fly test. Previous studies of adult stereoacuity reported that a reduction of the Titmus fly test score was observed in five of 60 normal subjects. ${ }^{18}$ All tests were conducted at a distance of $40 \mathrm{~cm}$, under an illumination of 200 lux. The motor phenotype was determined according to the UPDRS motor score, using the method prescribed by Jankovic et al. ${ }^{19}$

The general cognitive status of each subject was evaluated by means of the MMSE and the Clinical Dementia Rating (CDR) scale at baseline and two years later. ${ }^{20}$ For analytic purposes, the total daily L-dopa equivalent dose (total LEDD, mg/day) after two years was calculated based on theoretical equivalence from the literature. ${ }^{21}$ Dementia was diagnosed according to the Movement Disorders Society criteria of PD dementia, defined as impairment of $\geq$ two cognitive domains using neuropsychological tests associated with significant functional impairment from cognitive decline. $^{22}$ Detailed cognition was evaluated using the Seoul Neuropsychological Screening Battery, ${ }^{23}$ which consists of an attention test (forward digit span, backward digit span and letter cancellation), a language and related function test (spontaneous speech, comprehension, repetition, naming measured by the Korean version of the Boston Naming test, reading, writing, finger naming, right-left orientation, body part identification, calculation and praxis), a visuospatial function test (drawing an interlocking pentagon and the Rey complex figure test), a verbal memory test (three word registration, three word recall, and the Seoul Verbal Learning Test which included immediate recall, delayed recall, and recognition), a non-verbal memory test (immediate recall, delayed recall and recognition of a Rey complex figure) and a frontal executive function test (motor impersistence, contrasting program, go-no-go test, fist-edge-palm, alternating hand movement, alternating square and triangle test, Luria loop, Controlled Oral Word Association Test: animal, supermarket and letter, Korean-color Word Stroop Test: word reading and color reading).

\section{Statistical analysis}

The data were expressed as mean \pm standard deviation (SD) or as $\mathrm{n}(\%)$. Simple bivariate analyses were performed to identify potential predictors of cognitive decline. Non-categorical clinical variables including age were dichotomized at the median. Between-group comparisons were made using the Student's t-test or one-way analysis of variance (ANOVA). In the second stage of analysis, variables significantly associated with cognitive decline in the bivariate analyses $(P$ value of $\leq 0.05)$ were entered into a logistic regression analysis, using dementia conversion as the dependent variable. A backward stepwise method was used to remove non-significant predictors. All analyses were performed using Statistical Package for the Social Sciences (SPSS) 12.0 for Windows.

\section{RESULTS}

\section{Baseline and clinical characteristics}

A total of 80 patients were enrolled in the study. The mean (SD) interval of follow-up assessments from initial 
Table 1: Demographic and baseline clinical data in dementia-converter and non-converter

\begin{tabular}{|c|c|c|c|c|}
\hline & All participants $(\mathbf{N}=\mathbf{8 0})$ & Non-converters $(\mathrm{N}=62)$ & Dementia-converters $(\mathrm{N}=18)$ & $p$ \\
\hline Sex (male, \%) & $30,37.5 \%$ & $25,40.3 \%$ & $4,22.2 \%$ & $0.045^{*}$ \\
\hline Age (years) & $68.1 \pm 10.8(62)$ & $65.7 \pm 11.4$ & $73.8 \pm 6.3$ & $0.041 *$ \\
\hline Education (years) & $5.9 \pm 3.4(5)$ & $6.6 \pm 3.1$ & $3.2 \pm 3.3$ & 0.290 \\
\hline Disease duration (months) & $29.8 \pm 26.8(26)$ & $28.4 \pm 20.1$ & $31.3 \pm 21.3$ & 0.194 \\
\hline MMSE & $27.9 \pm 3.6(28)$ & $28.7 \pm 1.8$ & $24.0 \pm 3.2$ & $0.008 *$ \\
\hline H\&Y stage & $2.8 \pm 1.3(2)$ & $2.2 \pm 0.9$ & $3.17 \pm 0.7$ & 0.838 \\
\hline UPDRS I & $4.9 \pm 2.8(3)$ & $3.58 \pm 1.9$ & $7.17 \pm 2.4$ & 0.508 \\
\hline UPDRS II & $10.3 \pm 5.4(8)$ & $10.6 \pm 5.7$ & $8.78 \pm 4.8$ & 0.217 \\
\hline UPDRS III & $12.6 \pm 7.7(12)$ & $11.0 \pm 8.2$ & $16.4 \pm 6.3$ & $0.025 *$ \\
\hline NMSS & $21.1 \pm 10.3(19)$ & $19.6 \pm 9.9$ & $22.2 \pm 11.0$ & 0.424 \\
\hline
\end{tabular}

Data $=$ mean \pm SD (median), $*$ Significant difference

assessment was $2.2(0.4)$ years. The demographic and clinical characteristics are shown in Table 1. Dementia-converting group had significant low MMSE scores, older age and higher UPDRS motor scores at baseline.

\section{MMSE decline over two years}

The mean MMSE score (mean \pm SD) at initial evaluation was $27.9 \pm 3.6$, and the mean decline of the MMSE score was $2.7 \pm 2.6$ in 2 years. The mean decline of the MMSE score over 2 years in the dementia converting group $(6.6 \pm 1.7)$ was significantly higher than that of non-converting group $(1.4 \pm 1.2)(p<0.001)$. Among the non-motor symptoms, vivid dreaming $(p=0.021)$, RBD $(p=0.003)$, constipation $(p=0.043)$, hyposmia $(p=0.002)$, abnormal stereopsis $(p=0.001)$ and depression $(p=0.002)$ were associated with a more rapid rate of cognitive decline. Old age ( $\geq 62$ years, median age, $p<0.001)$, female gender $(p=0.048)$, non-smoking $(p=0.007)$, postural instability/ gait disturbance (PIGD) phenotype $(p<0.001)$ and severe motor dysfunction (UPDRS III score $>12, p<0.001$ ) were also associated with a more rapid rate of cognitive decline. Table 2 summarizes the bivariate analyses of clinical variables versus rate of cognitive decline over two years.

\section{Risk factors of dementia conversion}

Logistic regression analysis demonstrated that vivid dreaming, $\mathrm{RBD}$, hyposmia, depression and abnormal stereopsis were significant independent predictors of dementia risk within two years. The total score of NMSS was not an independent predictor of dementia risk. Old age (age $\geq 62$ years), PIGD phenotype and motor disability (UPDRS III score $>12$ ) were also significant independent predictors of dementia risk over two years. Table 3 summarizes the logistic regression results of the factors predicting dementia converting.

\section{DISCUSSION}

Dementia associated with PD is a common complication, affecting $80 \%$ of PD patients during the course of their illness. ${ }^{24}$ In our present study, $22.5 \%$ (18/80) of enrolled patients met the criteria of PD dementia at 24 months. A PD cohort study in
Table 2: Bivariate comparisons of demographic and clinical variables versus rate of cognitive decline over two years (change in MMSE), using the Student's t-test or ANOVA

\begin{tabular}{|c|c|c|}
\hline Variable & $\begin{array}{c}\text { Changes of MMSE over } 2 \text { years, } \\
\text { Mean } \pm \text { SD }\end{array}$ & $p$ value \\
\hline \multicolumn{3}{|l|}{ Dementia conversion } \\
\hline $\begin{array}{l}\text { Non-converter } \\
(\mathrm{n}=62)\end{array}$ & $1.4 \pm 1.2$ & $<0.001 *$ \\
\hline Converter $(\mathrm{n}=18)$ & $6.6 \pm 1.7$ & \\
\hline \multicolumn{3}{|l|}{ Sex } \\
\hline Male $(n=30)$ & $2.0 \pm 2.3$ & $0.048 *$ \\
\hline Female $(\mathrm{n}=50)$ & $3.1 \pm 2.7$ & \\
\hline \multicolumn{3}{|l|}{ Age } \\
\hline$<62$ years $(\mathrm{n}=23)$ & $1.2 \pm 1.5$ & $<0.001 *$ \\
\hline$\geq 62$ years $(n=57)$ & $3.7 \pm 2.7$ & \\
\hline \multicolumn{3}{|l|}{ Smoking } \\
\hline Yes $(n=19)$ & $1.3 \pm 1.4$ & $0.007 *$ \\
\hline No $(n=61)$ & $3.1 \pm 2.7$ & \\
\hline \multicolumn{3}{|l|}{ Alcohol } \\
\hline Yes $(n=20)$ & $2.0 \pm 2.3$ & 0.162 \\
\hline No $(n=60)$ & $2.9 \pm 2.6$ & \\
\hline \multicolumn{3}{|l|}{ Vivid dream } \\
\hline Presence $(n=38)$ & $3.4 \pm 2.7$ & $0.021 *$ \\
\hline Absent $(n=42)$ & $2.1 \pm 2.4$ & \\
\hline \multicolumn{3}{|l|}{ RBD } \\
\hline Presence $(n=35)$ & $3.7 \pm 1.6$ & $0.003 *$ \\
\hline Absent $(n=45)$ & $2.0 \pm 2.3$ & \\
\hline \multicolumn{3}{|l|}{ Visual hallucination } \\
\hline Presence $(n=8)$ & $3.6 \pm 2.6$ & \\
\hline Absent $(n=72)$ & $2.6 \pm 2.6$ & 0.287 \\
\hline \multicolumn{3}{|l|}{ Orthostatic dizziness } \\
\hline Presence $(n=33)$ & $2.5 \pm 2.6$ & 0.479 \\
\hline Absent $(n=47)$ & $2.9 \pm 2.6$ & \\
\hline
\end{tabular}


Table 2. (Continued)

\begin{tabular}{|c|c|c|}
\hline Variable & $\begin{array}{c}\text { Changes of MMSE over } 2 \text { years, } \\
\text { Mean } \pm \text { SD }\end{array}$ & $p$ value \\
\hline \multicolumn{3}{|l|}{ Constipation } \\
\hline Presence $(n=33)$ & $3.4 \pm 2.7$ & $0.043 *$ \\
\hline Absent $(n=47)$ & $2.2 \pm 2.4$ & \\
\hline \multicolumn{3}{|l|}{ Depression } \\
\hline Presence $(n=35)$ & $3.7 \pm 2.9$ & $0.002 *$ \\
\hline Absent $(n=45)$ & $1.9 \pm 2.1$ & \\
\hline \multicolumn{3}{|l|}{ Hyposmia } \\
\hline Presence $(n=33)$ & $3.8 \pm 2.7$ & $0.002 *$ \\
\hline Absent $(n=47)$ & $2.0 \pm 2.3$ & \\
\hline \multicolumn{3}{|l|}{ Abnormal stereopsis } \\
\hline Presence $(n=35)$ & $3.6 \pm 2.7$ & $0.001 *$ \\
\hline Absent $(n=45)$ & $1.6 \pm 1.9$ & \\
\hline \multicolumn{3}{|l|}{ Motor phenotype } \\
\hline PIGD $(n=26)$ & $5.2 \pm 2.6$ & $<0.001 *$ \\
\hline Non-PIGD $(\mathrm{n}=54)$ & $1.5 \pm 1.6$ & \\
\hline \multicolumn{3}{|l|}{ LED, 2 year follow-up } \\
\hline $0-150(n=46)$ & $2.1 \pm 2.5$ & 0.109 \\
\hline $151-250(\mathrm{n}=20)$ & $3.2 \pm 2.9$ & \\
\hline $251-500(n=7)$ & $3.9 \pm 1.8$ & \\
\hline $500<(\mathrm{n}=7)$ & $4.0 \pm 2.6$ & \\
\hline \multicolumn{3}{|l|}{ HY stage } \\
\hline $1-2$ & $1.4 \pm 1.4$ & $<0.001 *$ \\
\hline $3-5$ & $4.5 \pm 2.8$ & \\
\hline \multicolumn{3}{|l|}{ UPDRS I } \\
\hline$\leq 3$ & $1.7 \pm 1.6$ & $0.001 *$ \\
\hline$>3$ & $3.1 \pm 2.8$ & \\
\hline \multicolumn{3}{|l|}{ UPDRS II } \\
\hline$\leq 8$ & $2.7 \pm 2.4$ & 0.666 \\
\hline$>8$ & $2.7 \pm 2.7$ & \\
\hline \multicolumn{3}{|l|}{$\begin{array}{l}\text { UPDRS III } \\
\end{array}$} \\
\hline$\leq 12$ & $1.3 \pm 1.5$ & $<0.001 *$ \\
\hline$>12$ & $4.1 \pm 2.7$ & \\
\hline \multicolumn{3}{|l|}{ NMSS } \\
\hline$\leq 19$ & $1.9 \pm 2.3$ & 0.215 \\
\hline$>19$ & $3.4 \pm 2.7$ & \\
\hline
\end{tabular}

$\mathrm{RBD}=\mathrm{REM}$ sleep behavior disorders; $\mathrm{LED}=$ levodopa equivalent dose; $\mathrm{HY}=$ Hoehn and Yahr; PIGD = postural instability and gait disturbance; UPDRS = Unified Parkinson's disease rating scale; NMSS = Non-motor symptoms scale; $\mathrm{CI}=$ confidence interval; $\mathrm{B}=$ regression coefficient; S.E $=$ standard error; Wald. $=$ Wald statistic; $\mathrm{df}=$ degree of freedom; Sig. $=$ significance $; \operatorname{Exp}(B)=$ expected regression coefficient *Significant difference

Cambridge reported that the overall proportion of patients with dementia at 3.5 years is $10 \% .{ }^{25}$ A systematic review of prevalence studies of dementia in PD determined the prevalence to be $31.5 \% .^{26}$ Differences in study design, age and disease stage of subjects may account for these variations. The conversion rate to dementia of our study is relatively high. Our study was not a community based study but an hospital based study. Difference in study design may be considered as an explanation of high conversion rate.

Vivid dreaming, RBD, hyposmia, abnormal stereopsis and depression were significant NMS PD dementia predictors at 24 months in this study. These NMS are also associated with a more rapid rate of cognitive decline. Several cross-sectional and prospective studies show that RBD is associated with increased risk of dementia. ${ }^{27,28}$ A recent three-year longitudinal study demonstrated that severe olfactory dysfunction is a prodromal symptom of PD dementia. ${ }^{29}$ Although the diagnoses of RBD and hyposmia were not based on polysomnogram or the objective smell test, our questionnaire-based study also showed that RBD and hyposmia were the most significant risk factors for PD dementia. Recently, we reported that deficits of stereopsis are common in drug-naïve PD patients, ${ }^{9}$ we also suggested that the neural correlate of stereopsis may lie in the non-dominant extra-striate visual cortex with voxel-based morphometric study and abnormal stereopsis implicated in cortical visual dysfunction as part of the NMS in PD. ${ }^{10}$ Visuospatial and perceptual deficits are more frequently observed in PD dementia patients experiencing pathological changes in the visual association area. ${ }^{30}$ These findings suggest that abnormal stereopsis, which is related to the visual association area, may be a predicting factor for dementia in PD. In this study, abnormal stereopsis was associated with increased risk of dementia. Although visual hallucinations are a well-known risk factor of PD dementia, we did not find a significant association between visual hallucinations and dementia conversion in our present study. Failure to detect a significant association is likely due to the subject characteristics in our study. The subjects of our study were drug-naïve patients, and the numbers of patients with visual hallucinations was small.

The most important risk factor for PD dementia among the demographic factors assessed is increasing age. In our present study, old age ( $\geq 62$ years), PIGD phenotype and PD motor dysfunction, reflected by UPDRS III scores, are also PD dementia predictors.

This study of 80 cognitively normal de novo PD patients, observed prospectively for two years, resulted in an average annual decline of 1.3 points of the MMSE score. The average annual decline of the MMSE score in the dementia converting group was 3.28 points, which is significantly higher than that of the non-converting group ( 0.72 points). These results are similar to previous studies. Presence of depression, vivid dreaming, RBD, hyposmia, abnormal stereopsis, non-smoking and the PIGD phenotype were associated with a significantly more rapid decline of MMSE.

It must be acknowledged that there were several limitations to the current study. One limitation includes the dependence on subjective scale of NMS. The presence of olfactory dysfunction and RBD are dependent on subjective or caregiver recall. The second limitation is a short follow-up duration. A 2-year follow-up period is not adequate to assess advanced PD patients. Performing an extended follow-up study is therefore necessary.

With increased awareness of the non-motor risk factors for the development of dementia in PD, clinicians may be better able to 


\section{Table 3: Logistic regression results to predict dementia conversion}

\begin{tabular}{|c|c|c|c|c|c|c|c|c|}
\hline & & & & & & & \multicolumn{2}{|c|}{ 95\% C.I. for $\operatorname{EXP}(B)$} \\
\hline & B & S.E & Wald & df & Sig. & $\operatorname{Exp}(B)$ & Lower & Upper \\
\hline Age $>62$ & 2.4 & 1.1 & 4.9 & 1 & $0.027 *$ & 10.6 & 1.3 & 86.1 \\
\hline Female & 1.8 & 0.6 & 3.5 & 1 & 0.063 & 3.2 & 0.9 & 11.2 \\
\hline PIGD & 3.6 & 0.8 & 22.6 & 1 & $<0.001 *$ & 38.3 & 8.5 & 172.4 \\
\hline Vivid dreaming & 1.4 & 0.6 & 5.7 & 1 & $0.017 *$ & 4.2 & 1.3 & 13.4 \\
\hline RBD & 1.7 & 0.6 & 7.7 & 1 & $0.005^{*}$ & 5.4 & 1.6 & 17.5 \\
\hline Visual hallucination & 1.1 & 1.0 & 1.2 & 1 & 0.273 & 3.1 & 0.4 & 24.0 \\
\hline Orthostatic dizziness & -0.2 & 0.6 & 0.2 & 1 & 0.693 & 0.8 & 0.3 & 2.4 \\
\hline Constipation & 0.6 & 0.6 & 1.3 & 1 & 0.251 & 1.9 & 0.6 & 5.6 \\
\hline Depression & 1.6 & 0.6 & 6.9 & 1 & $0.008^{*}$ & 0.2 & 0.1 & 0.7 \\
\hline Hyposmia & 1.6 & 0.6 & 6.9 & 1 & $0.008 *$ & 4.9 & 1.5 & 15.9 \\
\hline Abnormal stereopsis & 2.6 & 0.8 & 10.7 & 1 & $0.001 *$ & 13.9 & 2.9 & 67.1 \\
\hline UPDRS I $>3$ & 1.2 & 0.7 & 3.1 & 1 & 0.078 & 3.4 & 0.9 & 13.2 \\
\hline UPDRS II $>8$ & -0.4 & 0.6 & 0.6 & 1 & 0.417 & 0.6 & 0.2 & 1.9 \\
\hline UPDRS III > 12 & 2.2 & 0.7 & 10.4 & 1 & $0.001 *$ & 9.4 & 2.4 & 36.9 \\
\hline NMSS $>19$ & 0.6 & 0.5 & 1.2 & 1 & 0.277 & 1.8 & 0.6 & 5.5 \\
\hline
\end{tabular}

PIGD = postural instability and gait disturbance; $\mathrm{RBD}=\mathrm{REM}$ sleep behavior disorders; UPDRS = Unified Parkinson's disease rating scale; NMSS $=$ Nonmotor symptoms scale; $\mathrm{CI}=$ confidence interval; $\mathrm{B}=$ regression coefficient; $\mathrm{S} . \mathrm{E}=$ standard error; Wald. $=$ Wald statistic; $\mathrm{df}=\mathrm{degree}$ of freedom; Sig. $=$ significance; $\operatorname{Exp}(\mathrm{B})=$ expected regression

*Significant difference

actively monitor cognitive dysfunction in their PD patients who present with the particular risk factors detailed in this study.

\section{REFERENCES}

1. Levy G, Tang MX, Louis ED, et al. The association of incident dementia with mortality in PD. Neurology. 2002;59(11):1708-13.

2. Playfer JR. Depression, cognition and quality of life in parkinsonian patients. Age Ageing. 1999;28(4):333-4.

3. Aarsland D, Larsen JP, Karlsen K, Lim NG, Tandberg E. Mental symptoms in Parkinson's disease are important contributors to caregiver distress. Int J Geriatr Psychiatry. 1999;14(10):866-74.

4. Aarsland D, Larsen JP, Tandberg E, Laake K. Predictors of nursing home placement in Parkinson's disease: a population-based, prospective study. J Am Geriatr Soc. 2000;48(8):938-42.

5. Hobson P, Meara J. Risk and incidence of dementia in a cohort of older subjects with Parkinson's disease in the United Kingdom. Mov Disord. 2004;19(9):1043-9.

6. Burn DJ, Rowan EN, Allan LM, Molloy S, O'Brien JT, McKeith IG. Motor subtype and cognitive decline in Parkinson's disease, Parkinson's disease with dementia, and dementia with Lewy bodies. J Neurol Neurosurg Psychiatry. 2006;77(5):585-9.

7. Apaydin H, Ahlskog JE, Parisi JE, Boeve BF, Dickson DW. Parkinson disease neuropathology: later-developing dementia and loss of the levodopa response. Arch Neurol. 2002;59(1):102-12.

8. Kim JS, Oh YS, Lee KS, Kim YI, Yang DW, Goldstein DS. Association of cognitive dysfunction with neurocirculatory abnormalities in early Parkinson disease. Neurology. 2012;79(13):1323-31.

9. Kim SH, Park JH, Kim YH, Koh SB. Stereopsis in drug naive Parkinson's disease patients. Can J Neurol Sci. 2011;38(2):299-302.

10. Koh SB, Suh SI, Kim SH, Kim JH. Stereopsis and extrastriate cortical atrophy in Parkinson's disease: a voxel-based morphometric study. Neuroreport. 2013;24(5):229-32.

11. Meppelink AM, de Jong BM, Renken R, Leenders KL, Cornelissen $\mathrm{FW}$, van Laar T. Impaired visual processing preceding image recognition in Parkinson's disease patients with visual hallucinations. Brain. 2009;132(Pt 11):2980-93.
12. Hughes AJ, Daniel SE, Kilford L, Lees AJ. Accuracy of clinical diagnosis of idiopathic Parkinson's disease: a clinico-pathological study of 100 cases. J Neurol Neurosurg Psychiatry. 1992;55(3): 181-4.

13. Hoehn MM, Yahr MD. Parkinsonism: onset, progression and mortality. Neurology. 1967;17(5):427-42.

14. The Unified Parkinson's Disease Rating Scale (UPDRS): status and recommendations. Mov Disord. 2003;18(7):738-50.

15. Ahn Y, Lee KY, Yi JS, et al. A validation study of the Koreanversion of Mongomery-Asberg depression rating scale. J Korean Neuropsychiatr Assoc. 2005;44(4):466-76.

16. Yesavage JA, Brink TL, Rose TL, et al. Development and validation of a geriatric depression screening scale: a preliminary report. J Psychiatr Res. 1982;17(1):37-49.

17. Stiasny-Kolster K, Mayer G, Schafer S, Moller JC, HeinzelGutenbrunner M, Oertel WH. The REM sleep behavior disorder screening questionnaire-a new diagnostic instrument. Mov Disord. 2007;22(16):2386-93.

18. Garnham L, Sloper JJ. Effect of age on adult stereoacuity as measured by different types of stereotest. $\mathrm{Br} \mathrm{J}$ Ophthalmol. 2006;90(1):91-5.

19. Jankovic J, McDermott M, Carter J, et al. Variable expression of Parkinson's disease: a base-line analysis of the DATATOP cohort. The Parkinson Study Group. Neurology. 1990;40(10):1529-34.

20. Kang Y, Na DL, Hahn MA. A validity study on the Korean mini-mental state examination (K-MMSE) in dementia patients. J Korean Neurol Asso. 1997;15(2):300-8.

21. Herzog J, Volkmann J, Krack P, et al. Two-year follow-up of subthalamic deep brain stimulation in Parkinson's disease. Mov Disord. 2003;18(11):1332-7.

22. Dubois B, Burn D, Goetz C, et al. Diagnostic procedures for Parkinson's disease dementia: recommendations from the movement disorder society task force. Mov Disord. 2007;22(16):2314-24.

23. Ahn HJ, Chin J, Park A, et al. Seoul Neuropsychological Screening Battery-dementia version (SNSB-D): a useful tool for assessing and monitoring cognitive impairments in dementia patients. J Korean Med Sci., 25(7):1071-6. 
24. Hely MA, Reid WG, Adena MA, Halliday GM, Morris JG. The Sydney multicenter study of Parkinson's disease: the inevitability of dementia at 20 years. Mov Disord. 2008;23(6):837-44.

25. Williams-Gray CH, Foltynie T, Brayne CE, Robbins TW, Barker RA. Evolution of cognitive dysfunction in an incident Parkinson's disease cohort. Brain. 2007;130(Pt 7):1787-98.

26. Aarsland D, Zaccai J, Brayne C. A systematic review of prevalence studies of dementia in Parkinson's disease. Mov Disord. 2005; 20(10): 1255-63.

27. Vendette M, Gagnon JF, Decary A, et al. REM sleep behavior disorder predicts cognitive impairment in Parkinson disease without dementia. Neurology 2007;69(19):1843-9.
28. Postuma RB, Bertrand JA, Montplaisir J, et al. Rapid eye movement sleep behavior disorder and risk of dementia in Parkinson's disease: a prospective study. Mov Disord. 2012;27 (6):720-6.

29. Baba T, Kikuchi A, Hirayama K, et al. Severe olfactory dysfunction is a prodromal symptom of dementia associated with Parkinson's disease: a 3 year longitudinal study. Brain. 2012;135 (Pt 1):161-9.

30. Mosimann UP, Mather G, Wesnes KA, O'Brien JT, Burn DJ, McKeith IG. Visual perception in Parkinson disease dementia and dementia with Lewy bodies. Neurology. 2004;63(11): 2091-2096. 